\title{
Impact of agriculture on the selection of insecticide resistance in the malaria vector Anopheles gambiae: a multigenerational study in controlled conditions
}

Theresia Estomih Nkya ${ }^{1,2,3}$, Rodolphe Poupardin ${ }^{4}$, Frederic Laporte ${ }^{1,2}$, Idir Akhouayri ${ }^{1,2}$, Franklin Mosha ${ }^{5}$, Stephen Magesa ${ }^{3,6}$, William Kisinza ${ }^{3}$ and Jean-Philippe David ${ }^{1,2^{*}}$

\begin{abstract}
Background: Resistance of mosquitoes to insecticides is mainly attributed to their adaptation to vector control interventions. Although pesticides used in agriculture have been frequently mentioned as an additional force driving the selection of resistance, only a few studies were dedicated to validate this hypothesis and characterise the underlying mechanisms. While insecticide resistance is rising dramatically in Africa, deciphering how agriculture affects resistance is crucial for improving resistance management strategies. In this context, the multigenerational effect of agricultural pollutants on the selection of insecticide resistance was examined in Anopheles gambiae.

Methods: An urban Tanzanian An. gambiae population displaying a low resistance level was used as a parental strain for a selection experiment across 20 generations. At each generation larvae were selected with a mixture containing pesticides and herbicides classically used in agriculture in Africa. The resistance levels of adults to deltamethrin, DDT and bendiocarb were compared between the selected and non-selected strains across the selection process together with the frequency of $k d r$ mutations. A microarray approach was used for pinpointing transcription level variations selected by the agricultural pesticide mixture at the adult stage.

Results: A gradual increase of adult resistance to all insecticides was observed across the selection process. The frequency of the L1014S kdr mutation rose from 1.6\% to 12.5\% after 20 generations of selection. Microarray analysis identified 90 transcripts over-transcribed in the selected strain as compared to the parental and the non-selected strains. Genes encoding cuticle proteins, detoxification enzymes, proteins linked to neurotransmitter activity and transcription regulators were mainly affected. RT-qPCR transcription profiling of candidate genes across multiple generations supported their link with insecticide resistance.

Conclusions: This study confirms the potency of agriculture in selecting for insecticide resistance in malaria vectors. We demonstrated that the recurrent exposure of larvae to agricultural pollutants can select for resistance mechanisms to vector control insecticides at the adult stage. Our data suggest that in addition to selected target-site resistance mutations, agricultural pollutants may also favor cuticle, metabolic and synaptic transmission-based resistance mechanisms. These results emphasize the need for integrated resistance management strategies taking into account agriculture activities.
\end{abstract}

Keywords: Agriculture, Pesticide, Pollutant, Mosquito, Anopheles gambiae, Malaria, Insecticide resistance, Detoxification enzymes, Cuticle, Kdr mutation

\footnotetext{
* Correspondence: jean-philippe.david@ujf-grenoble.fr

'Laboratoire d'Ecologie Alpine, UMR CNRS 5553, BP 53, 38041 Grenoble cedex 09, France

${ }^{2}$ Université Grenoble-Alpes, Grenoble, France

Full list of author information is available at the end of the article
}

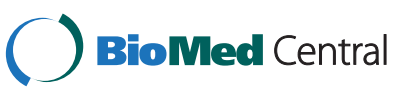

(c) 2014 Nkya et al.; licensee BioMed Central Ltd. This is an Open Access article distributed under the terms of the Creative Commons Attribution License (http://creativecommons.org/licenses/by/4.0), which permits unrestricted use, distribution, and reproduction in any medium, provided the original work is properly credited. The Creative Commons Public Domain Dedication waiver (http://creativecommons.org/publicdomain/zero/1.0/) applies to the data made available in this article, unless otherwise stated. 


\section{Background}

Malaria vector control programmes have shown success in the last few years through the use of chemical insecticides presented as insecticide treated bed nets (ITNs) or indoor residual spraying (IRS). These tools have been shown to be effective in reducing malaria transmission $[1,2]$. However, this success is now threatened by the rise of resistance in malaria vectors across Africa [3]. Over the years, resistance of malaria vectors to insecticides has been attributed to the intensive use of ITNs and IRS [4-7]. However, an increasing number of studies suggested that the use of pesticides in agriculture contributes to the selection of resistance in mosquitoes, threatening the efficacy of vector control interventions [8-14]. In Africa, agriculture sector accounts for $60 \%$ of employment with large areas of intensive agriculture. In addition to intensive agriculture, the rapid growth of African cities also led to the development of small-scale urban agriculture with uncontrolled use of pesticides [14,15]. As most insecticides used in agriculture are of the same chemical classes and share the same targets and modes of action as those used for vector control, they have the potential to select for resistance in mosquitoes [12]. Indeed, adults resting on crops treated with pesticides may undergo a significant selection pressure. However, the agricultural selection pressure may differ from the ones caused by vector control activities in term of mode of exposure (larvae likely exposed to agrochemical leachates versus adults only targeted by vector control) and the nature of chemicals (complex mixtures of agrochemicals versus single insecticide molecules), which may select for different resistance phenotypes although this has not been deeply investigated.

Resistance of mosquitoes to chemical insecticides involves various mechanisms. The best-known mechanism is target-site mediated resistance which involves nonsynonymous mutations affecting the proteins targeted by insecticides. Several target-site mutations have been described in malaria vectors including the $k d r$ (knock down resistance) mutations of the sodium channel conferring resistance to pyrethroids and DDT [16-19], the ace1 mutation of the acetylcholinesterase conferring resistance to organophosphates and carbamates $[10,20,21]$ and the $r d l$ mutation of the $\gamma$-aminobutyric acid (GABA) receptor conferring resistance to cyclodiens [22]. Although more complex and less well characterized at the molecular level, metabolic resistance is also frequent in mosquitoes and consists of an improved bio-degradation of the insecticide through metabolic processes. This mechanism classically involves 'detoxification' enzymes such as cytochrome P450 monooxygenases (P450s or CYPs for genes), glutathione S-transferases (GSTs) and carboxy/cholinesterases (CCEs) [12,23,24], although other enzyme families may also be involved. To date several candidate genes encoding detoxification enzymes have been identified in resistant malaria vectors and some have been functionally validated as insecticide metabolizers [25-29]. Other resistance mechanisms such as cuticle alteration, altered transport and sequestration are also likely to occur in resistant mosquito populations but their molecular characterization remains limited.

In Africa, resistance to insecticides such as DDT and pyrethroids has frequently been associated with pesticide usage in agriculture [11,14,30,31]. In Benin An. gambiae females were reported to frequently lay their eggs in breeding sites located around agricultural settings suggesting that larvae may undergo a selection pressure from agricultural pesticides, favouring the emergence of resistance [8]. In Tanzania, the resistance of Anopheles arabiensis to pyrethroids through metabolic resistance was associated with pesticide usage in an intensive agriculture area [30]. More recently, another Tanzanian field study comparing urban, agricultural and low pollution areas pinpointed the elevated resistance level of An. gambiae found in proximity of intensive agriculture and identified candidate genes associated with the use of pesticides in agriculture and insecticide resistance [32].

The use of agrochemicals may affect the resistance of mosquitoes to vector control insecticides in multiple ways review in [12]. First, insecticides used to protect crops and having the same targets and mode of action of those used for vector control may directly select for resistance mechanisms in mosquitoes. In addition, insecticides specifically used in agriculture may also select for cross-resistance mechanisms to those used for vector control. Finally, several studies have demonstrated that mosquito larvae exposed to sub-lethal doses of pollutants, herbicides or pesticides frequently display a higher tolerance to insecticides through the induction of their detoxifying system and possibly other mechanisms [33-35]. Recent data revealed that An. gambiae larvae exposed to a sub-lethal mixture of agrochemicals during their development show a strong increase of tolerance to deltamethrin at the larval stage and that this transient effect is passed through the adult stage (I. Akhouayri, personal communication). Although transient, such phenotypic plasticity may modulate the selection of particular resistance mechanisms by insecticides. Indeed, a study combining exposure to a non-toxic pollutant and selection with permethrin across several generations revealed different gene expression profiles between mosquitoes exposed to the pollutant before permethrin selection and those solely selected with permethrin [36]. Although the situation in natura is more complex, with chemical mixtures varying through time and space, the presence of agrochemicals in aquatic mosquito breeding sites is likely to affect the selection of genes conferring resistance of adult mosquitoes to insecticides used for vector control. 
In this context, the present study aimed at investigating the potency of agrochemicals in contact with An. gambiae larvae to select for resistance mechanisms in adults to the chemical insecticides used in vector control. For achieving this, an urban population of An. gambiae not previously exposed to agrochemicals and displaying low resistance levels to insecticides was artificially selected at the larval stage with a mixture of agrochemicals through several generations. Constitutive resistance levels of adults to three insecticides (deltamethrin, DDT and bendiocarb) were compared between the selected and the non-selected strain across the selection process and resistance mechanisms were investigated at the molecular level. Results are discussed with regards to the contribution of agriculture in the emergence and spread of insecticide resistance mechanisms in malaria vectors.

\section{Methods}

\section{Mosquitoes and selection procedure}

An An. gambiae population collected in summer 2011 from an urban site of Dar es Salaam (Ilala district, GPS coordinates S6.84643, E39.18285 as described in [32]) in east Tanzania was stabilized in the laboratory for 3 generations and then used as a parental strain for the selection experiment (generation $G_{0}$ ). To our knowledge, this population was not subjected to any recurrent agrochemical pollution. Mosquito control in this area consisted in IRS and ITN at a high coverage and malaria prevalence is around $3 \%$ [32]. A recent study indicates that this population displays a low resistance level to pyrethroid and DDT at the adult stage [32]. This population was composed of a mixture of An. gambiae sensu stricto (s.s.) and An. arabiensis, the former carrying the L1014S ' $k d r$ east' mutation at a low frequency $(1.6 \%,[32])$. No ace1 mutation was detected in this population [32]. Only An. gambiae s.s. were used to constitute the parental strain used for selection experiments. During the selection process, mosquitoes were reared in standard insectary conditions as described in [32]. Selection procedure consisted in exposing early L3 larvae for $24 \mathrm{~h}$ to a mixture of chemicals commonly used in agriculture at each generation. Agrochemical mixture was composed of various insecticides from different classes (organochlorines, organophosphates and pyrethroids), common pyrethroid metabolites [25] together with two herbicides (glyphosate and atrazine). These chemicals were chosen according to data gathered from local pesticide shops and individual farmers during a survey conducted in 2011 in northeast Tanzania (Theresia Nkya, unpublished data). The proportion of the different chemicals was determined according to concentrations classically found in water analyses in intensive agriculture areas and the relative toxicity of each compound. Composition of the agrochemical mixture is described in Table 1. For selection, the stock solution was diluted
10000 fold in order to reach a larval mortality between $50 \%$ and $80 \%$ after exposure. From the 7 th generation, this concentration was raised by 1.5 fold in order to maintain the selection pressure above $50 \%$. Selection was performed on replicates of 50 larvae in $50 \mathrm{~mL}$. At each generation, a minimum of 1000 larvae were used for selection. Selection procedure was carried out for 20 successive generations. In parallel, the parental strain was maintained in similar conditions without selection pressure (population size $\sim 500$ ).

\section{Bioassays with insecticides}

Comparative bioassays were conducted on the selected and the non-selected strain every 5 generations $\left(G_{0}\right.$ parental, $G_{5}, G_{10}, G_{15}, G_{20}$ ) to monitor the effect of the pesticide mixture on the resistance of adults to insecticides across the selection process. Three insecticides were used: the pyrethroid deltamethrin, the organochlorine DDT and the carbamate bendiocarb. In order to focus on constitutive resistance levels (inherited mechanisms), bioassays were performed on 3-5 days-old non-blood fed females not previously exposed to any xenobiotic (offspring of survivors for the selected strain). Bioassays were conducted according to WHO guidelines with plastic test tubes and insecticide impregnated papers at the following concentrations: $4 \%$ DDT, $0.05 \%$ deltamethrin, and $0.1 \%$ bendiocarb. Mosquitoes were exposed to each insecticide for varying durations $(5,10,20,30,45$ or $60 \mathrm{~min})$. For each exposure time, 4 replicates of 25 mosquitoes were used. After exposure, mosquitoes were allowed to recover with a $10 \%$ glucose solution for $24 \mathrm{~h}$ before recording mortality. Mortality was corrected using Abbot's Formula when the mortality rate of controls was between 5-20\%. Every five generations, the lethal time to kill $50 \%$ of individuals $\left(\mathrm{LT}_{50}\right)$ was calculated for each strain and each insecticide. The following bioassays could not be performed due to insufficient number of mosquitoes: deltamethrin $\mathrm{G}_{5}, \mathrm{DDT} \mathrm{G}_{10}$ and bendiocarb $\mathrm{G}_{10}$.

\section{Species identification and kdr genotyping}

Females from the initial parental strain $\left(G_{0}\right.$ individuals) and both the selected and the non-selected strains after 20 generations $\left(G_{21}\right.$ individuals) were subjected to species identification and $k d r$ mutation detection. Genomic DNA samples from 30 individual mosquitoes from each strain were analysed. Genomic DNA was extracted on individual mosquitoes by grinding and heating the mosquito at $65^{\circ} \mathrm{C}$ for 30 minutes in $100 \mu$ Bender buffer $(0.1$ $\mathrm{NaCl}, 0.2 \mathrm{M}$ sucrose, 0.1 M Tris- $\mathrm{HCl} \mathrm{pH} 7.5,0.05 \mathrm{M}$ EDTA pH 9.1, 0.5\% SDS) according to the method described by [37]. Species identification was performed following the PCR-based method described by [38]. The detection of East $k d r$ (L1014S) and West $k d r$ (L1014F) mutations was performed using the TaqMan ${ }^{\circ}$ PCR 
Table 1 Composition of the pesticide mixture used for selection

\begin{tabular}{|c|c|c|c|c|}
\hline Chemical class & Mosquito larvae toxicity* & $\begin{array}{l}\text { Stock solution } \\
(\mu \mathrm{g} / \mathrm{L})\end{array}$ & $\begin{array}{l}1 \mathrm{X} \text { dilution for selection } \\
(\mu \mathrm{g} / \mathrm{L})\end{array}$ & $\begin{array}{l}1.5 X \text { dilution for selection } \\
(\mu \mathrm{g} / \mathrm{L})\end{array}$ \\
\hline \multicolumn{5}{|l|}{ Organochlorine insecticides } \\
\hline DDT & medium & 2000 & 0.2 & 0.3 \\
\hline Endosulfan & medium & 2000 & 0.2 & 0.3 \\
\hline Lindane & low-medium & 10000 & 1 & 1.5 \\
\hline \multicolumn{5}{|l|}{ Organophosphate insecticides } \\
\hline Chlorpyriphos & high & 10 & 0.001 & 0.0015 \\
\hline Chlorfenvinphos & high & 10 & 0.001 & 0.0015 \\
\hline \multicolumn{5}{|l|}{ Pyrethroid insecticides } \\
\hline Deltamethrin & high & 10 & 0.001 & 0.0015 \\
\hline Permethrin & medium-high & 100 & 0.01 & 0.015 \\
\hline \multicolumn{5}{|l|}{ Pyrethroid metabolites } \\
\hline 3-phenoxybenzoic acid & not toxic & 20000 & 2 & 3 \\
\hline 3-phenoxybenzoic alcohol & not toxic & 20000 & 2 & 3 \\
\hline \multicolumn{5}{|l|}{ Herbicides } \\
\hline Glyphosate & not toxic & 20000 & 2 & 3 \\
\hline Atrazine & not toxic & 20000 & 2 & 3 \\
\hline
\end{tabular}

* I. Akhouayri, unpublished data.

diagnostic assays described in [39] and a MX3005P qPCR system (Agilent technologies).

\section{Transcription profiling using microarrays}

A microarray approach was used to identify adult transcription level variations associated with the selection of larvae with the agriculture pesticide mixture. The constitutive transcriptional profiles of the parental strain $\left(G_{0}\right.$ individuals $)$ and the non-selected and selected strains after 20 generations $\left(G_{21}\right.$ individuals) were compared using the AGAM $15 \mathrm{~K}$ microarray (Agilent technologies, array design A-MEXP-2196) representing more than $15 \mathrm{~K} \mathrm{An}$. gambiae transcripts. For each strain, three biological replicates of total RNA were extracted from pools of 10 three day-old non-blood fed adult females using the RNAqueous4PCR kit (Ambion). Total RNA was treated with DNaseI (Ambion) to remove genomic DNA. The quantity and integrity of RNA was analysed using a 2100 Bioanalyzer (Agilent). Hundred ng of total RNA were used for cDNA synthesis and T7-RNA amplification with Cy3- or Cy5-labelled CTPs using the 'Two-color Low Input Quick Amp' labelling kit (Agilent Technologies). Purified cRNAs were quantified and Cy3/Cy5 specific activity were measured using a Nanodrop ND1000 (NanoDrop Technologies). Pairwise hybridizations were performed between biological replicates of each strain with dye swaps for a total of 18 hybridizations ( 3 comparisons $x 3$ replicates $x$ 2 dye swaps). Hybridizations, slide washes and scanning were performed according to manufacturer's instructions. Spot finding, signal quantification and normalization were performed using the Agilent Feature Extraction software (Agilent Technologies). Normalized signal intensities were then loaded into Genespring GX version 12.5 (Agilent technologies) for further analysis. Spots showing a signal-to-noise ratio $>2$ for both colours were flagged 'detected' and only probes detected in at least $50 \%$ of hybridizations per comparison were considered for further analysis. For each pairwise comparison, transcription ratios (TRs) were $\log _{2}$ transformed and subjected to a one sample Student's t-test against the baseline value of 0 (equal gene expression in both strains) with a Benjamini-Hochberg FDR multiple testing correction. Transcripts with a TR $\geq 3$ fold in either direction and a $\mathrm{t}$-test adjusted $\mathrm{p}$-value $\leq 0.01$ between the selected and both the parental and the non-selected strain were considered differentially transcribed following selection with the pesticide mixture. Differentially expressed transcripts were then assigned to distinct categories according to their putative function as follows: amino acid and protein metabolism; lipid and carbohydrate metabolism; cuticle; detoxification; immunity; nervous system/hormones/messengers; expression regulation/chaperonin; structure/housekeeping; other. Transcripts belonging to each category were then submitted to a clustering analysis based on the Euclidean distance between $\log _{2}$ TR across each condition using TM4 MeV (http://www.tm4. org/mev.html). 


\section{Transcription profiling across the selection process using RT-qPCR}

The transcription profile of candidate genes was further examined across the selection process by comparing their transcription level in the selected and the non-selected strains at generations 10,15 and 21 by using RT-qPCR. RNA samples were extracted from three biological replicates of ten 3-5 days-old females per strain using the RNaqueous 4PCR total isolation kit (Ambion). Specific primers targeting each transcript were designed using NCBI Primer-Blast algorithm and their specificity checked against An. gambiae genome. Target transcripts included the two cytochrome P450s CYP4J10 and CYP6N1, the sulfotransferase AGAP009553, the multicopper oxidase AGA P003738, the cuticle protein AGAP010123 and the two heat shock proteins AGAP004583 and AGAP012891. Reverse transcription and $\mathrm{QPCR}$ reactions were performed as described in [32]. Data analysis was performed according to the $\Delta \Delta_{\mathrm{Ct}}$ method taking into account PCR efficiency [40] and using the housekeeping genes encoding the ribosomal proteins L8 (AGAP005802) and S7 (AGAP010592) for normalisation. Three technical replicates were performed per biological replicate and results were expressed as mean transcription ratio $\pm \mathrm{SD}$ relative to the nonselected strain.

\section{Results}

\section{Impact of larval selection on adult insecticide resistance levels}

Bioassays revealed that selecting An. gambiae larvae with the pesticide mixture increased their resistance to insecticides at the adult stage. A gradual increase of adult resistance to deltamethrin, DDT and bendiocarb was observed across the selection process (Figure 1). For deltamethrin, $\mathrm{LT}_{50}$ increased linearly from $3 \mathrm{~min}$ to $19.1 \mathrm{~min}$ (6.3 fold) after 20 generations of selection. A similar trend was observed when considering $\mathrm{LT}_{90}$ (4 fold). Resistance to DDT increased exponentially with $\mathrm{LT}_{50}$ rising from $2.8 \mathrm{~min}$ to 40.6 min after 20 generations ( 14.5 fold). A similar profile was observed with $\mathrm{LT}_{90}$ (13.6 fold). Likewise, an exponential increase of resistance to bendiocarb was observed with $\mathrm{LT}_{50}$ rising from $2 \mathrm{~min}$ to nearly $29.9 \mathrm{~min}$ (14.9 fold) and $\mathrm{LT}_{90}$ increasing by 10.8 fold.

\section{Species identification and kdr mutations frequency}

PCR diagnostic assays confirmed that all individuals constituting the parental strain and the two derived strains were An. gambiae sensu stricto. The $k d r$ west mutation (L1014F) was not detected in any strain. The frequency of the $k d r$ east mutation (L1014S) was estimated at $1.6 \%$ in the parental strain and increased to $12.5 \%$ after 20 generations of larval selection with the pesticide mixture (Table 2). In contrast, the frequency of this $k d r$ mutation decreased in absence of selection pressure as it was not

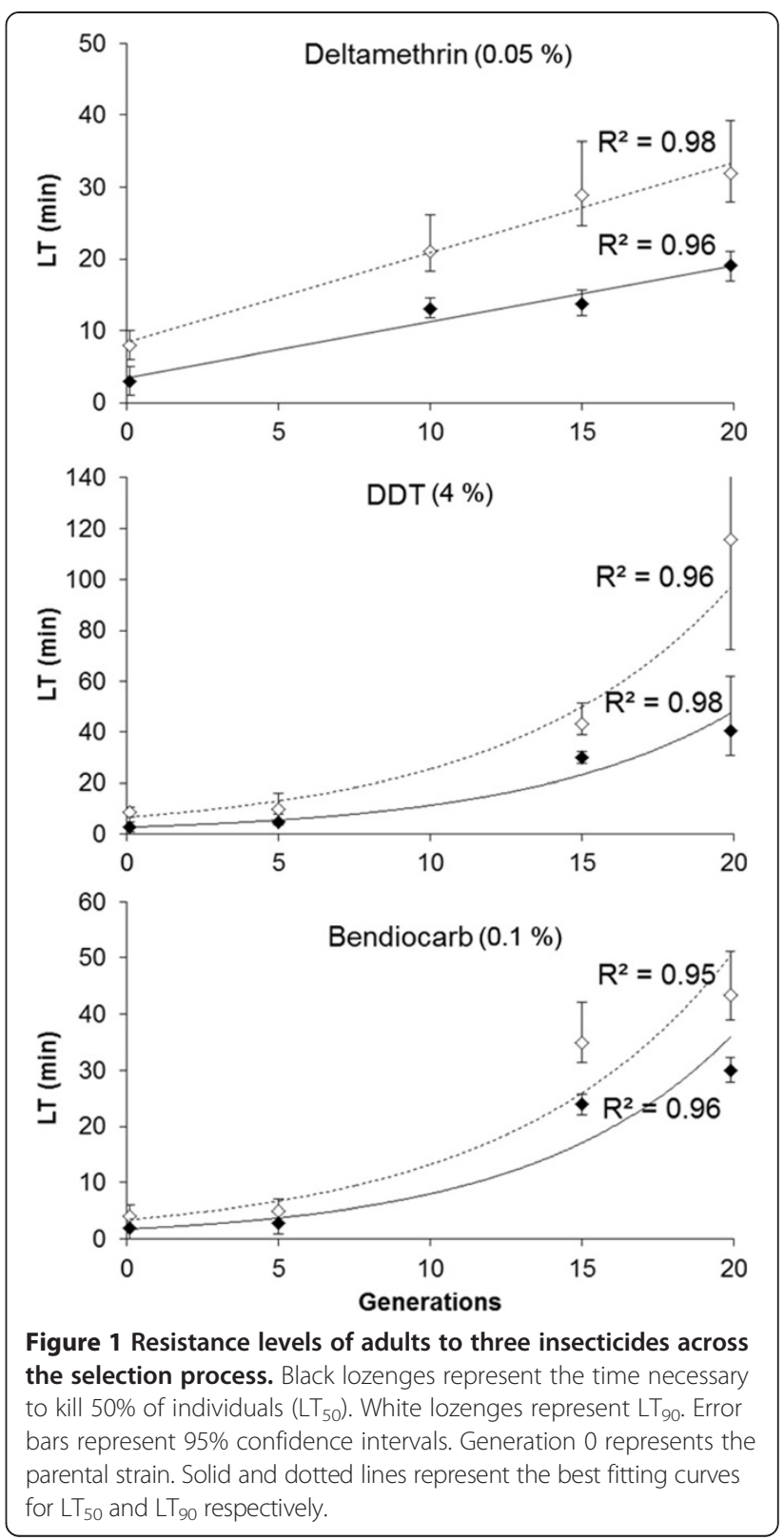

detected in the non-selected strain after 20 generations $(\mathrm{N}=30)$.

\section{Transcriptome profiling after $\mathbf{2 0}$ generations of selection}

Microarray analysis detected 9088 transcripts showing consistent signal to noise ratio in all strains, including 2740 being differentially transcribed in the selected strain as compared to the parental or the non-selected strains (TR $\geq 3$ and adjusted $P$ value $\leq 0.01$ ). Among those, 1338 transcripts were significantly over-transcribed in the selected strain versus other strains but only 90 transcripts were over-transcribed in the selected strain as compared to both the parental and the non-selected strains (Figure 2). Similarly, 1402 transcripts were under- 
Table 2 Evolution of kdr mutation frequency across generations

\begin{tabular}{|c|c|c|c|c|c|c|c|c|c|}
\hline \multirow[t]{2}{*}{ Strain } & \multicolumn{5}{|c|}{ Genotype at position 1014} & \multirow[t]{2}{*}{$\mathbf{N}$} & \multicolumn{3}{|c|}{ kdr allele frequencies (\%) } \\
\hline & $\mathrm{LL}$ & LS & SS & LF & $\mathrm{FF}$ & & L (wildtype) & $S$ (kdr east) & $F$ (kdr west) \\
\hline Parental & 29 & 1 & 0 & 0 & 0 & 30 & 98.4 & 1.6 & 0.0 \\
\hline Non-selected & 30 & 0 & 0 & 0 & 0 & 30 & 100.0 & 0.0 & 0.0 \\
\hline Selected $\mathrm{G}_{20}$ & 30 & 3 & 3 & 0 & 0 & 36 & 87.5 & 12.5 & 0.0 \\
\hline
\end{tabular}

transcribed in the selected strain versus other strains but only 4 of them were under-transcribed in the selected strain as compared to both the parental and the nonselected strains. Among the 94 transcripts differentially transcribed in the selected strain versus both the parental and the non-selected strains, only 64 were functionally annotated in Vectorbase. These transcripts encode protein families associated with various functions (Figure 2 and Additional file 1). Several of them were associated with nervous system functioning including multiple odorant binding proteins (18 transcripts). Others were associated with detoxification (7 transcripts), amino acid or protein metabolism (7 transcripts), lipid or carbohydrate metabolism (4 transcripts), expression regulation including heat shock proteins (6 transcripts), immunity (5 transcripts), cuticle (4 transcripts) and structure or housekeeping ( 5 transcripts). Most of these transcripts showed an over-transcription in the selected strain versus other strains but not in the non-selected strain as compared to the parental strain, suggesting that their increased expression is linked to the insecticide selection pressure (Figure 3). Among families classically associated with insecticide resistance, 3 cytochrome P450s (CYP4J10, CYP6N1 and CYP9L3) were significantly over-transcribed together with other enzymes potentially involved in insecticide degradation pathways ( 1 multicopper oxidase, 1 sulfotransferase, 1 superoxide dismutase and 1 nitrophenylphosphatase). A strong over-transcription of 4 cuticle proteins (CPLCG4, CPLCG5, CPLCG15 and CPR31) was also detected in the selected strain. An over-transcription of 3 transcripts encoding heat shock proteins showing high cDNA sequence identity among them was also detected. Among genes linked to nervous system functioning, 4 transcripts encoding alphacrystallins were strongly over-transcribed in the selected strain with the two pairs AGAP007159/007158 and AGAP005547/005548 showing very high cDNA sequence similarity. Several transcripts encoding odorant binding receptors (OBP51, OBP50, OBP10, OBP57, $O B P 54$ and $O B P 13)$ and one antennal carrier protein

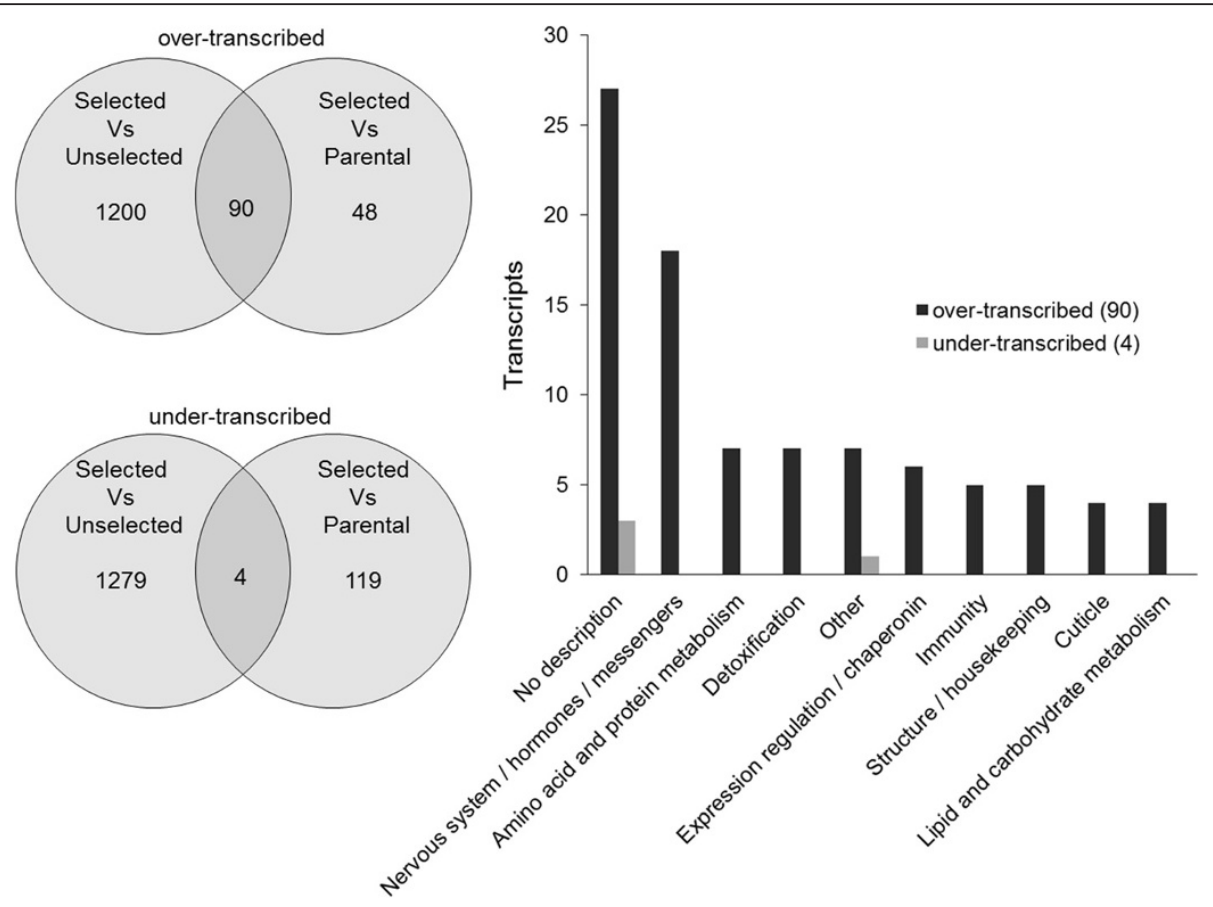

Figure 2 Overview of transcripts differentially expressed in the selected strain. The bar chart shows the biological categories represented by the 94 transcripts significantly over- or under-transcribed in the selected strain as compared to both the parental and the non-selected strains. 


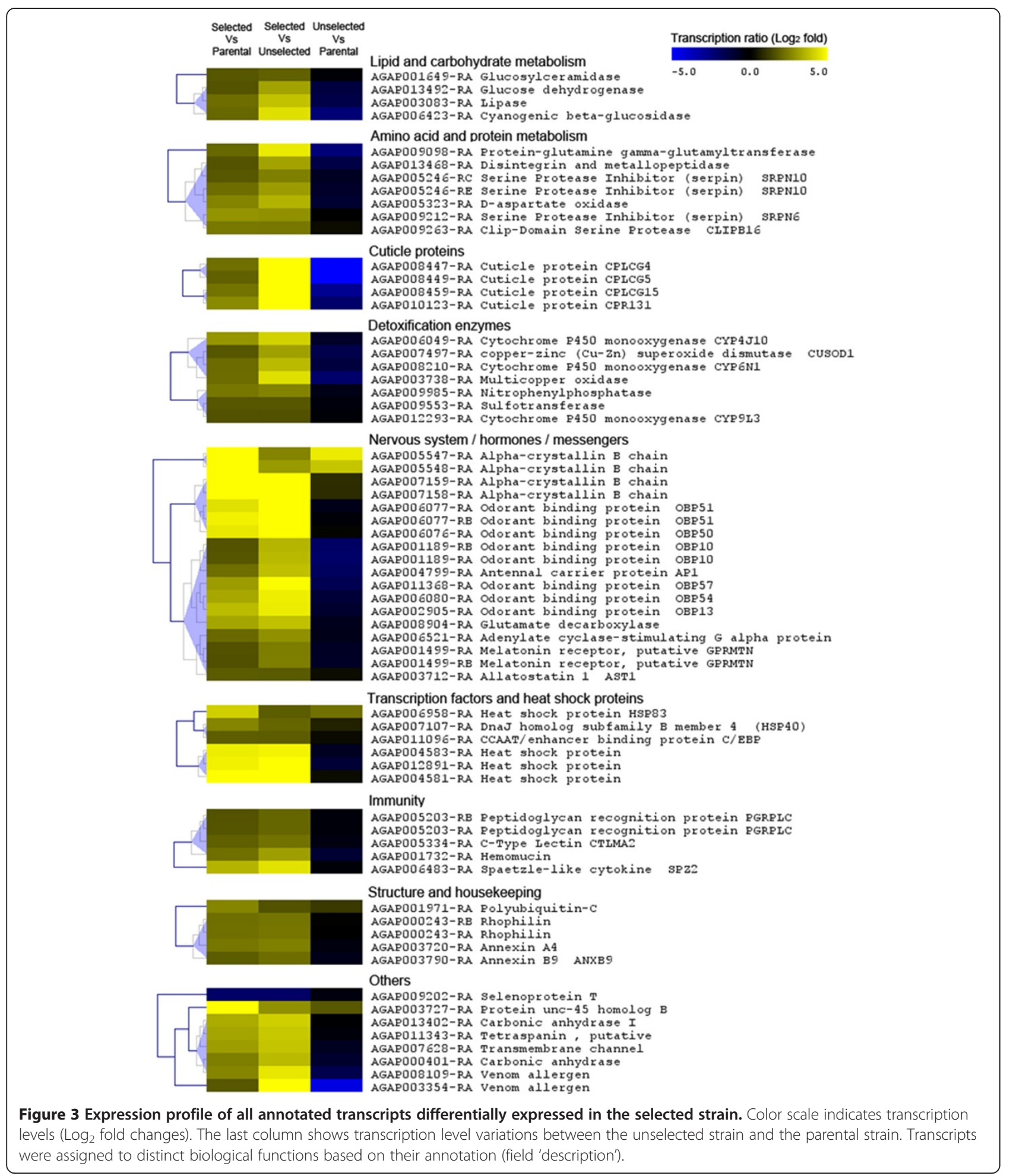

(AP1) were also over-transcribed in the selected strain. Finally the only annotated transcript being strongly under-transcribed in the selected strain encoded a thioredoxin-like protein called selenoprotein $\mathrm{T}$.
Transcription profiling of candidate genes across the selection process

Investigating the transcription profiles of six candidate genes across the selection process by RT-qPCR mostly 
confirmed microarray results (Figure 4). Among the six candidates the cytochrome P450 CYP4J10, the sulfotransferase AGAP009553, the multicopper oxidase AGAP003 738 displayed a progressive increased expression through the selection process. Although primer design did not allow us to distinguish between the two heat shock proteins AGAP004583 and AGAP012891, their expression profile also showed a gradual increase across the selection process. Even if high stochastic variations affected the expression profile of the cuticle protein AGAP010123, its over-transcription was confirmed starting from generation 15. Conversely, the cytochrome P450
CYP6N1 only showed a minor over-transcription in the selected strain with no gradual increase across the selection process.

\section{Discussion}

It has frequently been suggested that pesticides and other chemicals used in agriculture can favour the evolution of resistance of mosquitoes to insecticides used for their control although only few studies have been dedicated to demonstrate this phenomenon $[9,12,14]$. One hypothesis states that mosquito larvae may be recurrently exposed to agrochemicals leaching from crop

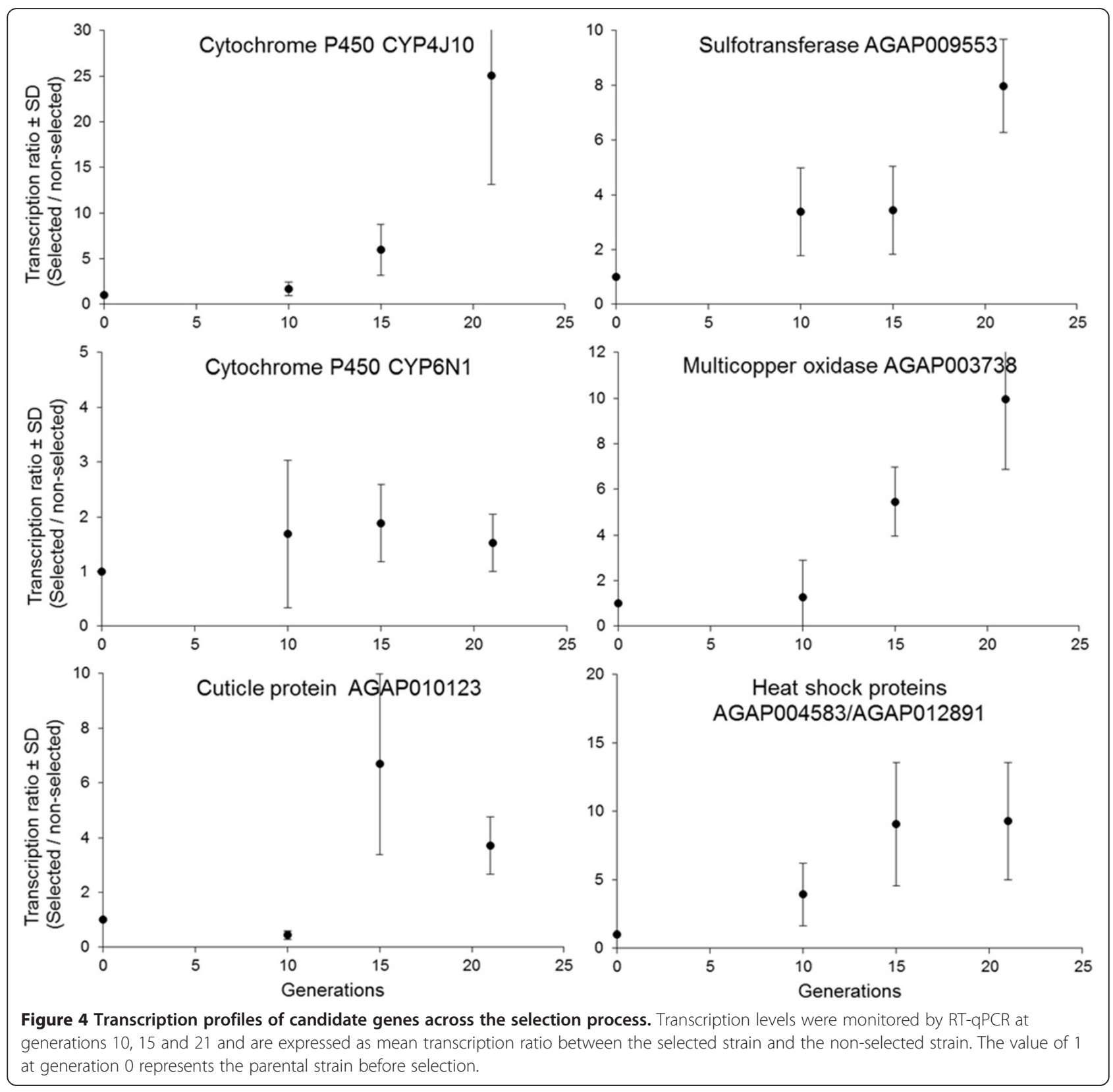


fields to their breeding sites leading to the selection of genes conferring resistance at the adult stage. The aim of the present study was to test this hypothesis in controlled conditions across multiple generations. To achieve this, a mixture of pesticides and agrochemicals classically found in water surrounding intensive agricultural areas was prepared. This mixture was then used for selecting a recently colonized An. gambiae population at the larval stage.

Bioassays confirmed that the repeated exposure of $A n$. gambiae larvae to chemicals used in agriculture can select for resistance against vector control insecticides in adults. Monitoring resistance levels along the selection process revealed that resistance to multiple insecticide classes increased significantly after only a few generations of selection. Although some insecticides present in the selection mixture are identical or share the same targets as those used for adult bioassays (sodium channel for pyrethroids and DDT, and acetylcholinesterase for organophosphates and bendiocarb), such rapid and concomitant rise of resistance to all insecticides was not expected. This suggests that multiple resistance mechanisms expressed at the adult stage can be rapidly selected even when selection targets the larval stage. Such multi-resistant phenotypes can be the consequence of the selection of different mechanisms with limited trade-off between them or the selection of particular genes conferring cross-resistance to different insecticide classes. Although deltamethrin and DDT both target the voltage-dependant sodium channel, resistance developed more rapidly for DDT (linearly up to 6 fold for deltamethrin and exponentially up to 14 fold for DDT) suggesting the L1014S $k d r$ east mutation is not the only cause of resistance. Regarding bendiocarb resistance, the absence of ace1 mutation in the parental strain $(\mathrm{N}=$ 50, [32]) suggests that other resistance mechanisms have been selected. Finally, this multi-resistant phenotype may have also been favoured by the low dose of each insecticide in the mixture, not toxic if taken individually, but showing a strong synergistic effect in the pesticide mixture used for selection (Idir Akhouayri, unpublished data).

Transcriptomics identified various biological functions affected by selection with the pesticide mixture. As expected, multiple transcripts encoding enzymes classically involved in detoxification processes were over-transcribed in response to selection. The gradual increased expression level of the cytochrome P450 monooxygenase CYP4J10 and the sulfotransferase AGAP009553 support their role in insecticide resistance as both have been associated with DDT resistance in An. gambiae [41]. The multicopper oxidase AGAP003738 is highly expressed in detoxification organs such as midgut and malpighian tubules [42] and has also been associated with DDT resistance [41]. In Aedes aegypti, a recent RNA-seq study identified a multicopper oxidase strongly over-transcribed in a strain resistant to the neonicotinoid insecticide imidacloprid [43] and slightly cross-resistant to DDT [44]. Surprisingly, no detoxification enzyme previously validated as deltamethrin or DDT metabolizer such as CYP6M2, CYP6P3 or GSTE2 [review in 26] were over-transcribed in the selected strain, suggesting that, besides the $k d r$ mutation, agricultural selection pressure undertaken by larvae may select for genes different to those selected for by the use of insecticides for vector control.

In addition to detoxification genes, multiple cuticle proteins (CPLCG4, CPLCG5, CPLCG15 and CPR131) increased in expression in the selected strain. The transcription level of two of them (CPLCG4 and CPLCG5) strongly decreased in absence of selection, suggesting that these genes were already under selection in the initial parental strain. Indeed, cuticle plays a crucial role in protecting insects from their environment; hence changes in cuticle thickness or conformation have been suggested to contribute to resistance in mosquitoes [45-47]. For instance, CPLCG4 has been frequently associated with insecticide resistance in malaria vectors $[46,48]$. A recent study supported its role in cuticle thickening, thus, possibly lowering the penetration of insecticides [49].

Two other functional categories were associated with pesticide mixture selection by transcriptomics. First, several transcription regulators, including five heat shock proteins (HSPs) and the CCAAT enhancer binding protein (C/EBP) AGAP011096 were over-transcribed after selection. These HSPs have been involved in response to thermal stress [50] and/or desiccation [51] but they were also found up-regulated in DDT-resistant field isolates [41] supporting their link with insecticide resistance and/ or stress response. C/EBPs are known for their key role in gene expression regulation and the over-transcription of the only one C/EBP found in An. gambiae may reflect the need for mosquitoes under pesticide selection to over-express a broad panel of proteins.

Finally, several genes linked to nervous system functioning, perception and messenger signalling were over-transcribed in the selected strain. These included crystallins, which are known to play a key role in eye transparency and neuron functioning [52-54]. Also included were six odorant binding proteins (OBPs) with some of them previously found over-transcribed in an An. gambiae DDT-resistant populations originating from cultivated areas [41]. Others include one G protein receptor together with a $\mathrm{G}$ protein-stimulating adenylate cyclase, the neuropeptide hormone allatostatin and a glutamate decarboxylase which catalyses the biosynthesis of the neurotransmitter $\gamma$-aminobutyric acid (GABA) through glutamate decarboxylation. Such 
impact of agricultural pesticides on mosquito nervous system functioning was previously evidenced from field populations collected in intensive agriculture areas [32]. Although these data need to be functionally validated, these results suggest that, in addition to known target-site mutations, the differential expression of other genes encoding proteins involved in nervous system functioning may contribute to the resistance phenotype.

\section{Conclusion}

Overall, our study demonstrated that mosquito larvae recurrently exposed to agricultural pesticide mixture can develop adult resistance mechanisms against vector control insecticides. This phenomenon occurred after only a few generations of selection and affected all tested insecticide classes. Transcriptomics revealed that a broad range of biological functions were affected including detoxification, cuticle, gene regulation and nervous system functioning. Although the present study did not allow dissecting the importance of each component of the mixture in the multi-resistant phenotype observed, the data confirmed the potential of agriculture in selecting for resistance in mosquitoes. These results strongly support the need for integrated vector resistance management strategies taking into account the use of pesticides in agriculture.

\section{Additional files}

Additional file 1: Table showing microarray data from all transcripts significantly differentially expressed in the selected strain. For each transcript, biological category together with fold changes and $P$ values are shown.

\begin{abstract}
Abbreviations
ITN: Insecticide-treated net; IRS: Indoor residual spraying; Kdr: Knock down resistance mutation; DDT: 4,4'-(2,2,2trichloroethane-1,1-diyl)bis (chlorobenzene); GABA: Gamma-aminobutyric acid; P450: Cytochrome P450 monooxygenase enzymes; CYP: Genes encoding cytochrome P450 monooxygenase; CCE: Carboxy/choline esterase; GST: Glutathione Stransferase; ace1: Acetylcholinesterase resistance mutation; WHO: World Health Organization; $L T_{50}$ : Lethal time killing $50 \%$ of individuals; $L T_{90}$ : Lethal time killing 90\% of individuals; CDNA: Complementary DNA; Cy3: Cynain-3 dye; Cy5: Cyanin-5 dye; CRNA: Complementary amplified RNA; TR: Transcription ratio; FDR: False discovery rate; RT-qPCR: Reverse transcription and quantitative polymerase chain reaction; NCBI: National Center for Biotechnology Information; OBP: Odorant binding receptor; HSP: Heat shock protein; C/EBP: CCAAT enhancer binding protein.
\end{abstract}

\section{Competing interests}

The authors declare that they have no competing interests.

\section{Authors' contributions}

T.N. conducted mosquito sampling, bioassays and molecular work, analysed results and drafted the manuscript. R.P. performed microarray hybridizations. F.L. performed RT-qPCR study. I.A. contributed to sample preparation and helped drafting the manuscript. S.M. and W.K. contributed to study design. J. P.D. conceived and coordinated the study, analysed results and wrote the manuscript. All authors read and approved the final manuscript.

\section{Acknowledgements}

The present study and T.N. research fellowship were funded by the EU FP7 project 'AvecNet' African Vector Control New Tools (EU grant agreement number 265660). We also acknowledge additional funding from the federative structure Environmental and Systems Biology (BEeSy) of Grenoble - Alpes University. We thank Prof. H. Ranson for valuable comments on the manuscript. We are also grateful to Dr. P. Müller for help with statistical analyses and microarray design. We also thank Mr. Omary Mpili for mosquito sampling, rearing and field work. For project management and administration we thank Dr. Eve Worrall and Dr. Denis Massue.

\section{Author details}

'Laboratoire d'Ecologie Alpine, UMR CNRS 5553, BP 53, 38041 Grenoble cedex 09, France. ${ }^{2}$ Université Grenoble-Alpes, Grenoble, France. ${ }^{3}$ National Institute of Medical Research of Tanzania. Amani Medical Research Centre, P. O. Box 81, Muheza, Tanga, Tanzania. ${ }^{4}$ Department of Vector Biology, Liverpool School of Tropical Medicine, Pembroke place, L35QA Liverpool, UK. ${ }^{5} \mathrm{KCM}$ College of Tumaini University, P. O. Box. 2240, Moshi, Tanzania. ${ }^{6}$ RTI International-Tanzania, P.O.Box 369, Dar es Salaam, Tanzania.

Received: 7 July 2014 Accepted: 6 October 2014

Published online: 16 October 2014

\section{References}

1. Pluess B, Tanser FC, Lengeler C, Sharp BL: Indoor residual spraying for preventing malaria. Cochrane Database Syst Rev 2010. Issue 4. Art. No: CD006657. doi:10.1002/14651858.

2. Lengeler C: Insecticide-treated bed nets and curtains for preventing malaria. Cochrane Database Syst Rev 2004. Issue 2. Art. No.: CD000363. doi:10.1002/14651858.

3. WHO: Global Plan for Insecticide Resistance Management in Malaria Vectors. Geneva, Switzerland: Publication of the World Health Organization; 2012:132.

4. Balkew M, Ibrahim M, Koekemoer LL, Brooke BD, Engers H, Aseffa A, Gebre-Michael T, Elhassen I: Insecticide resistance in Anopheles arabiensis (Diptera: Culicidae) from villages in central, northern and south west Ethiopia and detection of kdr mutation. Parasit Vectors 2010, 3:40.

5. Marcombe S, Mathieu RB, Pocquet N, Riaz M-A, Poupardin R, Selior S, Darriet F, Reynaud S, Yebakima A, Corbel V, David JP, Chandre F: Insecticide resistance in the dengue vector aedes aegypti from Martinique: distribution, mechanisms and relations with environmental factors. Plos One 2012, 7(2):e30989.

6. N'Guessan R, Corbel V, Akogbeto M, Rowland M: Reduced efficacy of insecticide-treated nets and indoor residual spraying for malaria control in pyrethroid resistance area, Benin. Emerg Infect 2007, 13:199-206.

7. Protopopoff N, Verhaeghen K, Van Bortel W, Roelants P, Marcotty T, Baza D, D'Alessandro U, Coosemans M: A significant increase in kdr in Anopheles gambiae is associated with an intensive vector control intervention in Burundi highlands. Trop Med Int Health 2008, 13:1479-1487.

8. Akogbeto MC, Djouaka RF, Kinde-Gazard DA: Screening of pesticide residues in soil and water samples from agricultural settings. Malar $J$ 2006, 5:22.

9. Antonio-Nkondjio C, Atangana J, Ndo C, Awono-Ambene P, Fondjo E, Fontenille D, Simard F: Malaria transmission and rice cultivation in Lagdo, northern Cameroon. T Roy Soc Trop Med H 2008, 102:352-359.

10. Antonio-Nkondjio C, Fossog BT, Ndo C, Djantio BM, Togouet SZ, AwonoAmbene P, Costantini C, Wondji CS, Ranson H: Anopheles gambiae distribution and insecticide resistance in the cities of Douala and Yaounde (Cameroon): influence of urban agriculture and pollution. Malar J 2011, 10:154

11. Diabate A, Baldet T, Chandre F, Akogbeto M, Guiguemde TR, Darriet F, Brengues C, Guillet P, Hemingway J, Small GJ, Hougard JM: The role of agricultural use of insecticides in resistance to pyrethroids in Anopheles gambiae SL in Burkina Faso. Am J Trop Med Hyg 2002, 67:617-622.

12. Nkya TE, Akhouayri I, Kisinza W, David J-P: Impact of environment on mosquito response to pyrethroid insecticides: Facts, evidences and prospects. Insect Biochem Mol Biol 2013, 43:407-416.

13. Nwane P, Etang J, Chouaibou M, Toto JC, Kerah Hinzoumbe C, Mimpfoundi R, Awono Ambene HP, Simard F: Trends in DDT and pyrethroid resistance in Anopheles gambiae s.s. populations from urban and agro-industrial settings in southern Cameroon. BMC Infect Dis 2009, 9:163. 
14. Yadouleton AWM, Asidi A, Djouaka RF, Braima J, Agossou CD, Akogbeto MC: Development of vegetable farming: a cause of the emergence of insecticide resistance in populations of Anopheles gambiae in urban areas of Benin. Malar J 2009, 8:103.

15. Keiser J, Utzinger J, De Castro MC, Smith TA, Tanner M, Singer BH: Urbanization in sub-Saharan Africa and implication for malaria control. Am J Trop Med Hyg 2004, 71:118-127.

16. Donnelly MJ, Corbel V, Weetman D, Wilding CS, Williamson MS, Black WCT: Does kdr genotype predict insecticide-resistance phenotype in mosquitoes? Trends Parasitol 2009, 25:213-219.

17. Martinez-Torres D, Chandre F, Williamson MS, Darriet F, Berge JB, Devonshire AL, Guillet P, Pasteur N, Pauron D: Molecular characterization of pyrethroid knockdown resistance $(\mathrm{kdr})$ in the major malaria vector Anopheles gambiae s.s. Insect Mol Biol 1998, 7:179-184.

18. Ranson H, Jensen B, Vulule JM, Wang X, Hemingway J, Collins FH: Identification of a point mutation in the voltage-gated sodium channel gene of Kenyan Anopheles gambiae associated with resistance to DDT and pyrethroids. Insect Mol Biol 2000, 9:491-497.

19. Jones CM, Liyanapathirana M, Agossa FR, Weetman D, Ranson H, Donnelly MJ, Wilding CS: Footprints of positive selection associated with a mutation (N1575Y) in the voltage-gated sodium channel of Anopheles gambiae. Proc Natl Acad Sci U S A 2012, 109:6614-6619.

20. Djogbenou L, Labbe P, Chandre F, Pasteur N, Weill M: Ace-I duplication in Anopheles gambiae: a challenge for malaria control. Malar J 2009, 8:70.

21. Essandoh J, Yawson A, Weetman D: Acetylcholinesterase (Ace-1) target site mutation $119 \mathrm{~S}$ is strongly diagnostic of carbamate and organophosphate resistance in Anopheles gambiae s.s. and Anopheles coluzzii across southern Ghana. Malar J 2013, 12:404.

22. Du W, Awolola TS, Howell P, Koekemoer LL, Brooke BD, Benedict MQ, Coetzee M, Zheng L: Independent mutations in the Rdl locus confer dieldrin resistance to Anopheles gambiae and An. arabiensis. Insect Mol Biol 2005, 14:179-183.

23. Hemingway J, Hawkes NJ, McCarroll L, Ranson H: The molecular basis of insecticide resistance in mosquitoes. Insect Biochem Mol Biol 2004, 34:653-665.

24. Li X, Schuler MA, Berenbaum MR: Molecular mechanisms of metabolic resistance to synthetic and natural xenobiotics. Annu Rev Entomol 2007, 52:231-253.

25. Chandor-Proust A, Bibby J, Regent-Kloeckner M, Roux J, Guittard-Crilat E, Poupardin R, Riaz MA, Paine M, Dauphin-Villemant C, Reynaud S, David JP: The central role of mosquito cytochrome P450 CYP6Zs in insecticide detoxification revealed by functional expression and structural modelling. Biochem J 2013, 455:75-85.

26. David J-P, Ismail HM, Chandor-Proust A, Paine MJl: Role of cytochrome P450s in insecticide resistance: impact on the control of mosquito-borne diseases and use of insecticides on Earth. Phil Trans Royal Soc B 2013, 368(1612):20120429.

27. Muller P, Warr E, Stevenson BJ, Pignatelli PM, Morgan JC, Steven A, Yawson AE, Mitchell SN, Ranson H, Hemingway J, Paine MJ, Donnelly MJ: Field-caught permethrin-resistant Anopheles gambiae overexpress CYP6P3, a P450 that metabolises pyrethroids. PLOS Genet 2008, 4:e1000286.

28. Mitchell SN, Stevenson BJ, Muller P, Wilding CS, Egyir-Yawson A, Field SG, Hemingway J, Paine MJ, Ranson H, Donnelly MJ: Identification and validation of a gene causing cross-resistance between insecticide classes in Anopheles gambiae from Ghana. Proc Natl Acad Sci U S A 2012, 109:6147-6152.

29. Chiu TL, Wen Z, Rupasinghe SG, Schuler MA: Comparative molecular modeling of Anopheles gambiae CYP6Z1, a mosquito P450 capable of metabolizing DDT. Proc Natl Acad Sci U S A 2008, 105:8855-8860.

30. Matowo J, Kulkarni MA, Mosha FW, Oxborough RM, Kitau JA, Tenu F, Rowland M: Biochemical basis of permethrin resistance in Anopheles arabiensis from Lower Moshi, north-eastern Tanzania. Malar J 2010, 9:193.

31. Ranson H, Abdallah H, Badolo A, Guelbeogo WM, Kerah-Hinzoumbe C, Yangalbe-Kalnone E, Sagnon NF, Simard F, Coetzee M: Insecticide resistance in Anopheles gambiae: data from the first year of a multicountry study highlight the extent of the problem. Malar J 2009, 8:299.

32. Nkya T, Akhouayri I, Poupardin R, Batengana B, Mosha F, Magesa S, Kisinza W, David J-P: Insecticide resistance mechanisms associated with different environments in the malaria vector Anopheles gambiae: a case study in Tanzania. Malar J 2014, 13:1-15.
33. David JP, Coissac E, Melodelima C, Poupardin R, Riaz MA, Chandor-Proust A, Reynaud S: Transcriptome response to pollutants and insecticides in the dengue vector Aedes aegypti using next-generation sequencing technology. BMC Genomics 2010, 11:216.

34. Poupardin R, Reynaud S, Strode C, Ranson H, Vontas J, David J-P: Crossinduction of detoxification genes by environmental xenobiotics and insecticides in the mosquito Aedes aegypti: Impact on larval tolerance to chemical insecticides. Insect Biochem Mol Biol 2008, 38:540-551.

35. Riaz MA, Poupardin R, Reynaud S, Strode C, Ranson H, David J-P: Impact of glyphosate and benzo a pyrene on the tolerance of mosquito larvae to chemical insecticides. Role of detoxification genes in response to xenobiotics. Aquatic Toxicol 2009, 93:61-69.

36. Poupardin R, Riaz MA, Jones CM, Chandor-Proust A, Reynaud S, David J-P: Do pollutants affect insecticide-driven gene selection in mosquitoes? Experimental evidence from transcriptomics. Aquatic Toxicol 2012, 114:49-57.

37. Collins FS, Drumm ML, Cole JL, Lockwood WK, Vandewoude GF, lannuzzi MC: Construction of a general human-chromosome jumping library, with application to cystic-fibrosis. Science 1987, 235:1046-1049.

38. Scott JA, Brogdon WG, Collins FH: Identification of single specimens of the Anopheles gambiae complex by the polymerase chain-reaction. Am J Trop Med Hyg 1993, 49:520-529.

39. Bass C, Nikou D, Donnelly MJ, Williamson MS, Ranson H, Ball A, Vontas J, Field LM: Detection of knockdown resistance (kdr) mutations in Anopheles gambiae: a comparison of two new high-throughput assays with existing methods. Malar J 2007, 6:111.

40. Pfaffl MW: A new mathematical model for relative quantification in real-time RT-PCR. Nucleic Acids Res 2001, 29(9):e45.

41. Tene BF, Poupardin R, Costantini C, Awono-Ambene P, Wondji CS, Ranson $\mathrm{H}$, Antonio-Nkondjio C: Resistance to DDT in an urban setting: common mechanisms implicated in both $\mathrm{M}$ and $\mathrm{S}$ forms of anopheles gambiae in the city of yaounde Cameroon. Plos One 2013, 8(4):e61408.

42. Baker DA, Nolan T, Fischer B, Pinder A, Crisanti A, Russell S: A comprehensive gene expression atlas of sex- and tissue-specificity in the malaria vector, Anopheles gambiae. BMC Genomics 2011, 12:296.

43. David JP, Faucon F, Chandor-Proust A, Poupardin R, Riaz MA, Bonin A, Navratil $V$, Reynaud S: Comparative analysis of response to selection with three insecticides in the dengue mosquito Aedes aegypti using mRNA sequencing. BMC Genomics 2014, 15:174.

44. Riaz MA, Chandor-Proust A, Dauphin-Villemant C, Poupardin R, Jones CM, Strode C, Régent-Kloeckner M, David J-P, Reynaud S: Molecular mechanisms associated with increased tolerance to the neonicotinoid insecticide imidacloprid in the dengue vector Aedes aegypti. Aquatic Toxicol 2013, 126:326-337.

45. Djouaka RF, Bakare AA, Coulibaly ON, Akogbeto MC, Ranson H, Hemingway J, Strode C: Expression of the cytochrome P450s, CYP6P3 and CYP6M2 are significantly elevated in multiple pyrethroid resistant populations of Anopheles gambiae s.s. from Southern Benin and Nigeria. BMCC Genom 2008, 9:538.

46. Vontas JDJ, Nikou D, Hemingway J, Christophides GK, Louis C, Ranson H: Transcriptional analysis of insecticide resistance in Anopheles stephensi using cross-species microarray hybridization. Insect Mol Biol 2007, 16:315-324

47. Wood ORHS, Coetzee M, Koekemoer LL, Brooke BD: Cuticle thickening associated with pyrethroid resistance in the major malaria vector Anopheles funestus. Parasit Vectors 2010, 3:67.

48. Awolola TS, Oduola OA, Strode C, Koekemoer LL, Brooke B, Ranson H: Evidence of multiple pyrethroid resistance mechanisms in the malaria vector Anopheles gambiae sensu stricto from Nigeria. T Royal Soc Trop Med H 2009, 103:1139-1145.

49. Vannini $\mathrm{L}$, Reed TW, Willis JH: Temporal and spatial expression of cuticular proteins of Anopheles gambiae implicated in insecticide resistance or differentiation of $\mathrm{M} / \mathrm{S}$ incipient species. Parasit Vectors 2014, 7:24.

50. Cassone BJ, Molloy MJ, Cheng CD, Tan JC, Hahn MW, Besansky NJ: Divergent transcriptional response to thermal stress by Anopheles gambiae larvae carrying alternative arrangements of inversion $2 \mathrm{La}$. Mol Ecol 2011, 20:2567-2580.

51. Wang MH, Marinotti O, Vardo-Zalik A, Boparai R, Yan GY: Genome-wide transcriptional analysis of genes associated with acute desiccation stress in anopheles gambiae. Plos One 2011, 6(10):e26011. 
52. Andley UP: Crystallins in the eye: Function and pathology. Prog Retin Eye Res 2007, 26:78-98.

53. Horwitz J, Bova MP, Ding L, Haley DA, Stewart PL: Lens [alpha]-crystallin: Function and structure. Eye 1999, 13:403-408.

54. Liedtke T, Schwamborn JC, Schroer U, Thanos S: Elongation of Axons during regeneration involves retinal crystallin beta b2 (crybb2). Mol Cell Proteomics 2007, 6:895-907.

doi:10.1186/s13071-014-0480-z

Cite this article as: Nkya et al:. Impact of agriculture on the selection of insecticide resistance in the malaria vector Anopheles gambiae: a multigenerational study in controlled conditions. Parasites \& Vectors 2014 7:480.

\section{Submit your next manuscript to BioMed Central and take full advantage of:}

- Convenient online submission

- Thorough peer review

- No space constraints or color figure charges

- Immediate publication on acceptance

- Inclusion in PubMed, CAS, Scopus and Google Scholar

- Research which is freely available for redistribution 